\title{
Токарев B.C. \\ Физическая подготовка как фактор, определяющий качество профессиональной деятельности и развития личности сотрудников Росгвардии
}

Новосибирский ордена Жукова военный институт имени генерала армии И.К. Яковлева войск наџиональной гвардии Российской Федераџии

(Россия, Новосибирск)

doi: 10.18411/trnio-12-2021-253

\section{Аннотация}

В статье рассматривается воздействие физической подготовки на профессиональную деятельность сотрудников Росгвардии. По мнению автора, физическая подготовка сотрудников Росгвардии должна быть направлена на формирование физически и нравственно здоровых специалистов, владеющих необходимым объемом специальных знаний, тактико-технических умений и навыков, физических и психических качеств, позволяющих успешно выполнять профессиональные задачи.

Ключевые слова: адаптация, воздействие, воспитание, личность, профессиональная деятельность, сотрудник, физическая подготовка, формирование, эффект.

\section{Abstract}

The article discusses the impact of physical fitness on professional activity of Rosgvardiya employees. According to the author, the physical training of Rosgvardiya employees should be aimed at the formation of physically and morally healthy specialists who prossess the necessary amount of special knowledge, tactical and technical skills, physical and mental qualities that allow them to successfully perform professional tasks.

Keywords: adaptation, impact, educated, personality, professional activity, physical training, formation, effect.

Физическая подготовка является одной из ведущих сторон служебно-боевой подготовки сотрудников Росгвардии. Широкий спектр профессиональных обязанностей с одной стороны требует постоянной готовности к крайним по сложности экстремальным ситуациям, связанным с пресечением преступлений, административных правонарушений и задержанием лиц, не выполняющих законные требования. Здесь перед сотрудниками Росгвардии стоит задача овладение специальными мерами пресечения (силовые приемы, специальные средства и огнестрельное оружие). Эффективность действий зависит от принятия мгновенных и верных, юридически правильных решений в сочетании с такими личностными качествами как смелость, решительность, хорошая координация движений, быстрота и сила.

В ряде теоретических и практических разработок по вопросам исследования специфики влияния физической подготовки на профессиональную деятельность сотрудников Росгвардии, обычно ставятся задачи выявления необходимых для ее выполнения умений и навыков, а также физических качеств. И в фундаментальном определении это понятие представляется только двумя его сторонами: обучение двигательным действиям (основа физического образования) и воспитание двигательных качеств (основа физического развития как процесса). Вместе с тем, без внимания остаются специфика профессиональной деятельности, развитие личности сотрудника, способы сохранения его здоровья и профессионального долголетия.

На основе усвоения элементов физической культуры, ее норм, ценностей, формируются социально значимые качества личности. К ним относятся скорость возникновения и устойчивость психических процессов, скорость восприятия и мышления, длительность ощущений, яркость воображения, интенсивность психических процессов (чувств, эмоций, воли) темп и ритм психической деятельности, направленность на 
межличностные, социальные контакты. Все эти особенности проявляются в мимике, жестах, эмоциональной окрашенности речи, разнообразных непроизвольных движениях и действиях.

Специфической особенностью физической подготовки в формировании личности сотрудника является: прикладность, основанная на естественно-биологических предпосылках; «перенос тренированности», формирование потребностей и способностей, освоение общественного опыта и социальных ценностей, которые обладают наибольшей практической значимостью для личности; подготовка к эффективному профессиональному труду и формирование здорового образа жизни.

Физическая подготовка сотрудника Росгвардии создает условия драматичности и конфликтности, напряжения и тревоги, без которых невозможно появление чувства ответственности. Физкультурно-спортивная деятельность, профессиональные, функциональные и культурные свойства личности соединены и определяют способ ее проявления в личности. Как система, физическая подготовка в развитии личности выступает:

- в целях (актуализация и развитие личностных функций);

- в содержании, в котором образовательный стандарт органически сочетается с личностным опытом обучаемого;

— в технологии, обеспечивающей востребованность личностных функций и личностного уровня саморегуляции обучаемого, его субъектную позицию в учебном процессе, личностное саморазвитие.

К основным функциям физической подготовки в формировании личности относятся: приобретение знаний, умений, навыков, развитие физических сил и способностей, а также формирование мировоззрения; развитие интеллекта, эмоционально-волевой и действеннопрактической сфер; формирование нравственности на основе сознательного усвоения морали общества; укрепление здоровья.

Направленное воздействие специальных двигательных режимов обеспечивает эффект «генеральной адаптации» будущего сотрудника, позволяющий более успешно входить в режим обучения в учебном заведении, противодействовать стрессовым факторам различного характера, укреплять социальный статус личности по мере получения образования, повышать авторитет в микросреде, привыкать к режиму ежедневной нагрузки.

Эффект предварительной адаптации. Этот эффект самый распространенный и доступный из воздействий, способных повысить результативность всех без исключения средств физической культуры и спорта. Эффект предварительной адаптации зависит от уровня приспособленности организма к условиям мышечной деятельности. Если такого восприятия нет, то занятия физическими упражнениями лишь повреждает функции организма. Способность воспринять влияние физических упражнений определяется уровнем развития двигательных способностей: чем выше физическая работоспособность, тем легче человеку выполнять различные физические упражнения и, естественно, воспринять их влияние. При низкой физической работоспособности организм может воспринять влияние лишь самых легких нагрузок.

Вместе с тем, увеличение потребности в физических упражнениях и физических факторах среды сопровождается снижением способности воспринимать их влияния. В отличие от медикаментозных воздействий, которые не требуют активности человека как необходимой предпосылки реализации влияния их на организм, физические упражнения могут оказать свое влияние лишь в том случае, если человек способен их выполнить.

Эффект восполнения. При однократном выполнении физических упражнений существенно улучшается функциональное состояние и самочувствие человека, испытывающего двигательную недостаточность. В условиях восполнения двигательного дефицита ритм работы сердца и артериальное давление снижаются, что указывает на более экономичный ритм работы сердечно-сосудистой системы и увеличение резервных возможностей организма. Эффект восполнения, несмотря на кратковременность влияния, при многократном повторении оказывает выраженное лечебное и профилактическое 
действие, существенно улучшая регуляцию функций не только сердечно-сосудистой системы, но и всего организма. В связи с этим, эффект восполнения можно рассматривать как адаптационный механизм начального этапа профилактических влияний двигательной активности.

Эффект избыточности. В процессе физического воспитания эффект избыточности успешно формируется за счет значительного количества упражнений и их повторений, против необходимого количества строго ограниченных действий в профессиональной деятельности. Характер профессиональной деятельности сотрудника Росгвардии нередко находится на грани человеческих возможностей. Избыточность двигательных действий в учебно-тренировочном процессе способствует расширению двигательного опыта, значительному увеличению функциональной активности мышц и соответственному увеличению функциональных резервов организма, развитию интуиции, что создает преимущества в чрезвычайных ситуациях.

Эффект тренированности. Всякое сокращение мышц позволяет нам благодаря сенсорным датчикам, которые расположены в нервных окончаниях мышц, сухожилий и суставных связок, чувствовать положение и движения собственного тела. Они информируют спинной мозг или двигательные центры более высокого уровня о том, какое напряжение развивает в данный момент мышца. Систематическое воздействие на нервные центры ведет к повышению работоспособности мышц и других звеньев опорно-двигательного аппарата и позволяет выполнять профессиональные действия, обеспечивает эффективную жизнедеятельность человека.

Вместе с тем, физические нагрузки оказывают тренирующий эффект тогда, когда они способны существенным образом изменить биохимические константы внутренней среды, то есть если они выводят организм из гомеостатического покоя на повышенные уровни гомеостазиса деятельности. Тренирующая нагрузка должна превышать привычную повседневную бытовую и производственную работу мышц. Физическая нагрузка в тренирующем режиме приводит к выработке и реализации ценнейших для жизнедеятельности организма рефлексов с мышц на внутренние органы: сердце, легкие, желудочно-кишечный тракт и печень.

Эффект закаливания. По механизму своего развития он близок к эффекту тренированности. Наиболее важными вариантами эффекта закаленности являются повышение приспособленности к холодовым воздействиям, преодоления уязвимости организма по отношению к тепловым, гравитационным воздействиям, а также к влиянию других неблагоприятных факторов окружающей среды. Эффект закаленности формируется в результате развития терморегуляции и проявляется в способности организма повышать (снижать) теплопродукцию, нейтрализуя тем самым значительные потери тепла (влаги) в результате охлаждения (перенагревания). Эффект закаливания проявляется в улучшении деятельности центральной нервной системы, что ведет к повышению умственной работоспособности человека. Под влиянием закаливающих процедур улучшается кровоснабжение головного мозга и, что особенно важно, повышается способность осуществлять эвристические действия при решении психологических задач. Тренировка механизмов терморегуляции улучшает сосудистые реакции, делает более экономичной легочную вентиляцию, увеличивает коэффициент использования кислорода и улучшает кислородтранспортную функцию крови.

Регуляторно-трофический эффект. Определено, что между интенсивностью физических нагрузок и величиной реакций кровообращения и дыхания существует прямая пропорциональная зависимость: чем интенсивнее мышечная работа, тем до более высокого уровня поднимаются и медленнее восстанавливаются реакции сердечно-сосудистой и дыхательной систем.

Это позволяет относительно, по сравнению с другими реакциями, уменьшить величину функционального напряжения, падающего на орган, то есть в известной мере, «обойти» его стимулирующими влияниями путем перераспределения усилий и включением 
дополнительных элементов в структуру двигательного действия. При этом механическая работа, выполняемая мышцами при использовании дополнительных элементов, больше, но организм «не ощущает» этого увеличения нагрузки.

Другой тип регуляторно-трофических эффектов обеспечивает направленное развитие «слабого звена» функции. Какая-либо функция, нуждающаяся в стимуляции, может быть избирательно усилена за счет специально подобранных воздействий, включаемых в занятия физическими упражнениями.

Эффект погашения. Переключение активности на иной двигательный стереотип вызывает срочное, немедленное уменьшение степени функционального напряжения важнейших систем организма. В результате этого утомительная работа в большей степени соответствует биологической природе человека, которой свойственно разнообразие движений, потребность избегать жестко закрепленных двигательных стереотипов.

Эффекты внутренних состояний. Сознание и движение в своих соотношениях не всегда носят равновесный характер. Человеческие движения как кинематика в объективном пространстве-времени преимущественно не являются сознательными актами. С их построением справляются досознательные когнитивные процессы. В свою очередь, динамика развития психических процессов и состояний человека, его ощущений, восприятия, памяти, мышления, воли, внимания, эмоций и чувств - в значительной степени определяется характером доминирующих видов деятельности, в том числе и двигательной.

При психо-эмоциональном подъеме человек может выходить за пределы своих возможностей. Так хождение «пестинарий» по горячим углям, невосприимчивость «моржей» к охлаждению при купании в ледяной воде и др. достигается во многом за счет психоэмоциональных воздействий.

Наряду с влиянием физических упражнений на биологические характеристики, остается весьма важным их влияния на социальную адаптацию личности, что не ограничивается только приобретением широкой номенклатуры специальных знаний, умений и качеств, но и проявляется в уровне и принципах мышления, позволяющих охватить общественно-исторический процесс во всем его многообразии и цельности.

Эффект «заражения». Среди психологических механизмов, лежащих в основе «заражения» физкультурно-спортивной деятельностью выделяют особое состояние поглощенности деятельностью, при котором ожидаемый результат этой деятельности отходит в сознании человека на задний план и само действие занимает все внимание.

Эффект творческой деятельности. Одним из эффектов, способных существенно повысить результативность занятий физическими упражнениями, являются осознание этих занятий как творческой деятельности. Объектом этой деятельности является организм человека, его функции и возможности, развиваемые физическими упражнениями до совершенства. Что может быть красивее всесторонне развитого человеческого тела, особенно если мы видим его в движениях демонстрирующих удивительные способности человека. Ведь красота есть форма, в которой проявляется биологическая целесообразность организма.

Понимание творческих эффектов физкультурной активности в профессиональной подготовке и развитии личности исключительно важно в практическом отношении. Чем лучше мы осознаем творческую сущность движений, тем больше сможем повысить преобразовательную результативность занятий физическими упражнениями. Чем больше в процессе физических упражнений будет творчества, тем больше заинтересованности в занятиях.

Эффект предметно-орудийной деятельности. Использование предметов, орудий и механических устройств (локомоции, поднимание тяжестей и метания, гимнастические и акробатические движения, упражнения любого вида спорта и т.д.) - это преодоление сил гравитации, что открывает широкие возможности увеличения результативности занятий физическими упражнениями. Эффективность физических упражнений при переходе от обычной деятельности к предметно-орудийной проявляется не только в облегчении 
выполнения движений, но и в существенном изменении самого восприятия нагрузки организмом. Каждый предмет или орудие стимулирует определенные, заданные движения. Это означает, что из безграничного множества движений, число которых определяется взаимодействием 639 мышц, 206 костей, имеющих приблизительно 150 соединений, предметы и орудия, отбирают совершенно конкретные.

Предметно-орудийная деятельность обеспечивает строгое направление движения и условия, облегчающие осуществление этого движения в определенном направлении, в результате чего включаются новые, не использовавшиеся человеком ранее степени свободы физической деятельности. Есть тренажеры «встраивающиеся» в систему регуляции функций организма с поврежденными звеньями. Они дают возможность реализовать эффекты, которые в естественных условиях не могут осуществляться.

\section{Эффект возрастающего взаимодействия или каскадный эффект.}

Развивающийся эффект воздействия физических упражнений означает не просто сохранение или возрастание первичного влияния. Это также усиление слабого воздействия в результате преобразования первоначально действующего стимула. Именно благодаря процессам такого рода «малая или отдаленная причина» приобретает способность проявиться в «огромнейшем влиянии». Основной областью, где реализуется влияние эффекта возрастающего взаимодействия, является закаливание. Именно в условиях профессиональной деятельности сотрудников, кратковременные занятия физическими упражнениями как бы вклиниваются между производственными нагрузками и изменяют характер их влияния на организм.

Исходя из вышеизложенного можно сделать вывод, что физическая подготовка сотрудников Росгвардии должна быть направлена на формирование физически и нравственно здоровых специалистов владеющих необходимым объемом специальных знаний, тактико-технических умений и навыков по силовому задержанию и огневому поражению противника, физических и психических качеств позволяющих успешно выполнять профессиональные задачи, а так же способности противостоять влиянию факторов профессиональной деформации и поддержание здорового образа жизни.

$$
* * *
$$

1. Баркалов С.Н. Методика служебно-боевой подготовки курсантов вузов МВД России с учетом специфики профессиональной деятельности: Автореф. дисс... канд. пед. наук.- М., 2005.- С. 11-13.

2. Курамшин Ю.Ф. Современные подходы к структуре физической культуры личности // Актуальные проблемы теории и практики физической культуры: Межвузовский сборник / Под общей ред. В.И. Григорьева.- СПб.: Изд-во СПбГУЭФ, 2004.- С. 68-73.

3. Макеева В.С., Куницын А.Д., Вучева В.В. Оздоровительно-рекреативная физическая культура: Учеб. пособие / Под ред. М.Я. Виленского. - Орел: Орел ГТУ, 2004. - 243 с.

4. Орлов В.А., Фудин Н.А. Комплексная программа оценки физического состояния и функциональных возможностей организма человека. - М.: Издательская группа «АриНА», 2003.- 72 с.

5. Полянский В.П. О сущности отношений прикладной физической культуры и служебной (профессиональной) деятельности // Вопросы совершенствования боевой подготовки в современных условиях: Мат. межвуз. науч.-практ. конф.- М.: МА МВД РФ, 2002.- С. 127-137.

\section{Труханова А.B.}

Развитие образовательных онлайн-платформ

\section{Рязанский государственный университет имени С.А.Есенина}

(Россия, Рязань)

doi: 10.18411/trnio-12-2021-254

\section{Аннотация}

В данной работе рассматривается развитие образовательных онлайн-платформ, возникших в условиях развития цифровой экономики. Такой вид обучения в настоящий момент набирает свою популярность. Особенно онлайн-платформы помогают не прерывать 